\title{
Original Research Article Study on the Influence of Tourism Activities on Nature Reserves in China and Its Countermeasures
}

\author{
Qi Ji \\ Beijing International Studies University, Beijing 100024, China
}

\begin{abstract}
China's "industrial restructuring" has expanded the proportion of the tertiary industry in the economy and promoted the development of local tourism. The ongoing "industrial structure upgrading" is intended to make the industry bigger and stronger, which will promote the growth of local tourism. As a tourist resort, nature reserves have been attracting a large number of tourists and have great development potential and economic value. Under this situation, various management agencies of nature reserves have successively carried out tourism activities and carried out tourism development and construction. However, there is no doubt that both tourism activities and development will have an impact on the ecological system of nature reserves. The existing legal system of nature reserves in China emphasizes the prohibition of behaviors that directly destroy the ecological environment and ignores the impact of human tourism activities. The continuous increase in the number of tourism in our country, brought on nature reserves of rich tourist income at the same time, a large number of facts show that tourism has become a source of environmental pollution, so it is necessary for tourism environmental pollution the main way to do a summary and its particularity, summing up the basic law of tourism affect the environment, thus provide the basis for strengthening the environmental protection from the point of view of tourism management. The emergence and development of tourism culture is inseparable from the influence of the environment, and tourism culture also affects the environment. The negative effects and negative effects of tourism culture development on the environment are becoming more and more evident, which has aroused people's general concern. In recent years, the negative impact of tourism and cultural activities on the environment has been paid much attention to by many scholars at home and abroad. This paper discusses the impact of tourism activities on nature reserves, and discusses the causes of this problem, so as to analyze the strategies to ensure the harmony and order of nature reserves in tourism activities.
\end{abstract}

Keywords: Tourism Activities; Nature Reserves; Impact

\section{Definition of nature reserves}

From the perspective of meaning, we can generally divide nature reserves into broad sense and narrow sense. Nature reserves are established in accordance with state rules and regulations. They are areas for the maintenance of biodiversity and the protection of geological structures. Generally speaking, a nature reserve is an area designed to protect some rare animals, plants and natural resources. The establishment of nature reserves is of great significance for preserving the original appearance of nature, protecting rare species and natural resources ${ }^{[1]}$. In general, both economically and culturally, nature reserves can play an important role ${ }^{[2]}$. In order to protect the objects within the protected area and maintain the harmony and order within the area, relevant activities in the nature reserve must be restricted to some extent ${ }^{[3]}$. In 1994, the State Council promulgated the Regulations on Nature Reserves, which clearly defined the concept of nature reserves. The regulations point out that nature reserves are natural concentrated areas of natural resources and rare and endangered species of wild animals and plants, which shall be designated by the state according to law and specially protected and managed by the state. China's nature reserves can generally be divided into three types, including core area, buffer zone and experimental area. Tourism activities are generally carried out in experimental areas. The nature reserve is also known as the "nature sanctuary" and the nature protected area. Nature reserves are usually the concentrated distribution areas of some rare and rare animal and plant species, the resting places for migratory birds to breed, overwinter or migrate, and the concentrated habitats of wild related species of some breeding animals and cultivated plants. They are typical or special ecosystems. It is also often a natural scenic spot with beautiful scenery, geological profiles, fossil sites or glacial traces, karst, waterfalls, hot springs, craters and meteorite sites of special protection value. The purpose of establishing nature reserves in China is to protect precious and rare animal resources as well as the ecosystem that represents the natural environment of different natural zones. It also includes cultural relics of special significance. Its significance lies in: preserving the natural background, which is the way to be followed in the future utilization and transformation of nature, providing people with evaluation criteria and predicting

This is an open-access article distributed under the terms of the Creative Commons Attribution Non-Commercial License

(http://creativecommons.org/licenses/by-nc/4.0/), which permits unrestricted non-commercial use, distribution, and reproduction in any medium, provided the original work is properly cited. 
the consequences of human activities; Reserve species, which are sanctuaries to save endangered species; Scientific research and education bases are important bases for studying the natural processes of various ecosystems, the ecology and biological characteristics of various organisms, as well as places for educational experiments. Preserve the aesthetic value of nature, which is the source of human health, inspiration and creation. Nature reserves are of great significance to the sustainable development of national economy and the development of science, technology and culture.

\section{The impact of tourism activities on nature reserves}

To some extent, tourism activities can improve the utilization value of the resources in the area, promote the economic development of the area, enhance the self-development ability of the area, and improve the visibility of the area. However, the negative effects of tourism activities are also very obvious. With the continuous development of tourism activities, various activities carried out by people in tourism activities have increased the burden of soil, affected the local ecological environment, and brought impact and damage to surface waters and soil[ ${ }^{[4]}$. Due to soil degradation and destruction, some surface vegetation in the nature reserve has also been impacted to a certain extent. In tourist activities, human's removal and trampling of vegetation directly affect the natural growth of local vegetation and harm the normal growth of aquatic plants. In many places, when planning pedestrian walkways, the designed routes are quite unreasonable, which results in the destruction of the normal growth environment of many endangered plants. Meanwhile, for those vegetation that has already grown, the morphology and physiology of vegetation will change after being trampled by tourists due to their neglect. Waste pollution in tourism activities will also indirectly cause the destruction of vegetation growth environment ${ }^{[5]}$. The development of tourism activities will also affect the normal life of wild animals. Some tourists, due to the lack of necessary awareness of environmental protection, make noise at will during tourism activities, which directly affects the normal life and reproduction of animals, as well as the living rules of local animals. Due to the restriction of tourists' quality and management force, the tourism in nature reserve has posed potential threats to the habitat survival of wild animals and plants, such as climbing branches, trampling vegetation, picking flowers and fruits, picking birds' eggs, using fire in the wild, and disturbing the animals. In addition, the entry of tourists also increases the spread of certain diseases common to humans and animals. At the same time, due to inadequate supervision, some tourists in the tourist activities into the public littering, everywhere are discarded by the tourists food plastic packaging bags, plastic mineral water bottles, cigarette butts and so on. These wastes are not only hard to be degraded, but also can be eaten by some birds, causing the death of wild animals. Ecotourism makes the management of protected areas more difficult. Nature reserve ecotourism can create economic benefits for protected areas on the one hand, on the other hand, along with the ecological tourism development and environmental pollution, bring some uncivilized activities and behavior of tourists, the impact of foreign culture, as well as the blindness of development will cause the interference and damage to its resources, to influence the normal management of protected areas, increase the management difficulty. How to provide healthy, safe and comfortable tourism products has become an urgent problem to be solved in nature reserves.

\section{Strategies to mitigate the negative effects of current tourism activities}

At present, the nature reserve has the social conditions for developing ecotourism. First, the construction of management institutions of nature reserves has been gradually strengthened; second, the construction of nature reserves has gradually moved to the track of legalization and standardization; third, the national economy has developed rapidly, and people's living standards have been improved, and the overall quality of life has been constantly improved. Therefore, the development and management of eco-tourism is particularly important. According to the current situation and characteristics of nature reserves in China and the existing problems in the process of developing eco-tourism, the following countermeasures and measures are proposed for the development and management of eco-tourism:

\subsection{Improve laws and regulations on nature reserves}

We will improve laws and regulations and strengthen law enforcement and supervision. The development and construction of ecological tourism in nature reserves should be brought into the legal track. Although the natural reserves ordinance and the forest and wildlife type nature reserve management method "and other relevant laws and regulations to the nature reserves to develop ecological tourism has made the corresponding provisions, but in the nature reserve ecotourism development principles, conditions, procedures, steps and measures is not detailed enough, still need to be perfected. In the relevant laws and regulations concerning nature reserves in China, although relevant provisions on tourism activities in the experimental areas of nature reserves should be reviewed, due to the early passage of the act and the impact of the social environment at that time, some specific issues related to tourism activities should be systematically stipulated. The act imposes strict legal measures on ACTS that directly destroy the country's nature reserves. Although these laws strictly prohibit the direct destruction of nature reserves, to some extent, they protect the impact of tourism activities on nature reserves. However, due to the early legislation of the act, insufficient attention has been paid to the impact of tourism activities on nature reserves in the planning of tourist routes. But nowadays the situation has changed fundamentally. The sharp increase in the number of tourists aggravates the problem of environmental pollution ${ }^{[6]}$. Therefore, to effectively deal with this threat in the future, it is necessary to legislate specific and detailed regulations on various tourism activities and improve the laws and regulations of nature reserves, so as to limit the pollution of tourism activities and realize sustainable development. First, laws need to be passed to guarantee the share of tourism revenues devoted to environmental protection in nature reserves. The purpose of tourism activities is to better promote the protection of local natural resources. Therefore, environmental pollution and other problems in tourism activities need to be solved through the income from tourism activities. The responsibilities of the managers of nature reserves also need to be further clarified, so that the relevant pollution and damage behaviors of nature reserves can be effectively dealt with reasonably and effectively. 


\subsection{To raise citizens' awareness of environmental protection}

In the relevant provisions of the nature reserve, the regions and standard conditions for carrying out ecotourism are clearly defined, and the guidelines for carrying out ecotourism in the experimental planning area are also stipulated. However, with the continuous development of China's tourism industry, more and more tourism activities are carried out, which requires more detailed and specific management of tourism activities, so that ecological protection can be carried out in a detailed way. In the development of tourism activities, how to ensure the environment of nature reserves, do a good job in ecological protection, we can learn from Japan some feasible countermeasures ${ }^{[7]}$. Japan has a large population density and little land resources, so the development of tourism activities is faced with environmental pressure brought by population pressure. Therefore, Japan has passed the Tourism Basic Law to regulate the behavior of tourists, and has made detailed provisions on the development and maintenance of tourism resources. Therefore, China can learn from Japan's practice and formulate the basic law of ecotourism to stipulate the rights and obligations of tourists and define the rights and responsibilities of regional tourism managers, so as to ensure the sustainable development of tourism areas ${ }^{[8]}$. At the same time, laws should be formulated together with other countries to guide the behavior of tourists, so that citizens can know their obligations when carrying out tourism activities and promote the improvement of citizens' awareness of environmental protection. Strengthen environmental education at the community level. In order to raise citizens' awareness of environmental protection, it is necessary for every group in the society to contribute their own efforts. Grassroots environmental education, as the basis for citizens to participate in environmental protection, is of great significance. Therefore, governments and relevant institutions must be fully aware of the importance of strengthening environmental education at the grass-roots level. The government and relevant departments should pay more attention to environmental education, transmit the latest environmental protection information to the grassroots, promote the socialization of environmental protection, and realize the citizenship of environmental awareness. At the same time, grassroots environmental education and environmental protection work will become more specific and vivid, and citizens' understanding of environmental protection will naturally be improved to a certain extent. Besides, citizens are more willing to participate in various social environmental protection activities subjectively and make their own contributions to environmental protection work. Laws and regulations such as the "Environmental Protection Law" and the "Regulations on Nature Reserves" should be widely publicized, and the idea that environmental protection is a basic state policy and a basic protection condition and strategic task in China's modernization drive should be established. It is necessary to improve the leading cadres' understanding of resources, ecology and the environment. In setting up projects for resource development, policy makers should have advanced knowledge, and the whole nation should have a better understanding of the environment. In environmental protection, the masses should be mobilized and supervised. We should deal with the relationship between resource protection and tourism development. All artificial production, management and other projects should take the protection of resources as the basic principle, that is, give priority to protection. We should firmly establish the principle of "protection first and sustainable development", coordinate economic construction with nature conservation, develop on the premise of protection, strengthen protection in utilization, pay attention to protection, develop moderately, plan reasonably and implement it step by step. The protection, development and construction of nature reserves shall be incorporated into the national economic plans and social development plans of local governments, and economic and technological policies and measures conducive to the protection of nature shall be adopted to coordinate the protection work with economic construction and social development.

\subsection{Improve the management system and strengthen environmental law enforcement}

At present, in the management of nature reserves in my country, most departments and units have established enterprises such as tourism, transportation and catering. However, the personnel rights and property rights of such enterprises belong to different investment units. It can be said that each travel agency belongs to different systems. As a result, the domestic tourism system is complicated, and there is a phenomenon of separate governance. Because the management body is very complicated. This makes it difficult to solve the environmental problems in nature reserves from the management level in a short time. However, through the reform of the management system, the management level of tourism waste pollution will also be continuously improved. Therefore, the relevant management departments can start with the management system to strengthen the ecological protection of nature reserves. When facing environmental problems such as garbage pollution caused by tourism activities, the management agencies of nature reserves need to formulate tourism garbage disposal systems to deal with the garbage produced by tourists during tourism activities ${ }^{[9]}$. At the same time, part of the tourism revenue will be invested in environmental protection, so as to recruit and clean up personnel to deal with tourism waste. The local administrative departments of environmental protection shall actively shoulder their own responsibilities, carry out regular environmental surveys in the areas of nature reserves where tourism is carried out, strengthen the construction of environmental law enforcement teams, and improve the level and capability of environmental law enforcement. To improve the specification and coordination capacity of environmental supervision agencies, we will strengthen the standardization and standardized management of environmental law enforcement teams and improve their law enforcement skills and capabilities. We will strengthen team management, publicize law enforcement information, improve law enforcement transparency, resolutely investigate and deal with typical cases involving violations of laws and regulations, improve personnel quality, build a competent, efficient, clean and civilized environmental law enforcement team with good political quality, familiarity with and correct use of environmental laws and regulations, and constantly improve the management system.

\subsection{We will move from the traditional economy to the modern ecological system}

The establishment of a benign circular environment ecosystem, the realization of ecological civilization strategic breakthrough, to the minimum consumption of natural resources and maximize the establishment of ecological system as a balanced development model, to maintain the healthy operation of economic and social development. Therefore, on the basis of traditional agriculture, we should popularize ecological industry, ecological forestry and take the road of ecological economic development. In order to realize 
the virtuous circle between the necessary economic development and the necessary ecological construction, both development and protection should be paid equal attention to, and the real breakthrough of sustainable development should be guaranteed.

\section{References}

1. Wei Xia. Research on diagnosis and countermeasures of ecotourism in my country's nature reserves [J]. Research on Soil and Water Conservation, 2003(03): 132-135.

2. Shen Bing. The impact of tourism development on Cang'er Nature Reserve and its countermeasures [J]. Environmental Science Guide, 1996(2): 24-28.

3. Jiang Mingkang, Wu Xiaomin. Research on ecotourism development and management countermeasures in nature reserves [J]. Journal of Ecology and Rural Environment, 2000(3).

4. Xie Yongqiu. The status quo of ecotourism in nature reserves in my country and sustainable development strategies [J]. Economics and Management Research, 2007(09): 87-90.

5. Ouyang Zhiyun, Wang Xiaoke. Discussion on the problems and countermeasures faced by the management system of nature reserves in my country [J]. Science and Technology Review, 2002, 20(021): 49-52.

6. Wang Hefei. Quantitative analysis and countermeasures of the impact of tourism disturbance on the vegetation of Tuoliang Yunding grassland [D]. Hebei Agricultural University, 2011.

7. Li Xiaojuan. Research on the impact of tourism activities on the ecological environment of Mount Everest National Nature Reserve [J]. 2015.

8. Xie Shouliang. Research on the impact and countermeasures of tourism activities in nature reserves in my country [C]// 2009 National Environmental Resources Law Seminar. 2009.

9. Cui Xianghui, Chu Jianmin, Li Shaoning, et al. The status quo and development and management strategies of ecotourism in nature reserves in my country [J]. World Forestry Research, 2006, 19(4): 57-60. 